\title{
QUADRINHOS NO LIVRO DIDÁTICO E O ENSINO-APRENDIZAGEM DE LÍNGUA ITALIANA
} Felipe de Souza Costa*

Resumo: Este trabalho propõe-se a analisar os quadrinhos e suas possiveis contribuições para o ensino da língua italiana. Para tanto, selecionamos, como corpus, o primeiro volume da coleção Progetto Italiano Junior. Interessa-nos saber como os quadrinhos são utilizados no referido livro e em que medida essa linguagem, explorada no livro, se coaduna a um ensino eficiente da língua-alvo por meio deles. Filiamo-nos aos estudos, principalmente, de Barbieri (1998), Cagnin (1975) e Ramos (2012), a fim de discutirmos os quadrinhos como uma linguagem, além de nos apoiarmos em Brasil (1998), Borneto (1998) e Pichiassi (1999) para a discussão a respeito da língua italiana num quadro de ensino-aprendizagem.

Palavras-chave: Quadrinhos. Italiano. Livro didático.

\section{CONSIDERAÇÕES INICIAIS}

Cremos que falta à escola ainda a coragem de incorporar as HQs ao conjunto dos vários objetos de leitura com que já trabalha, considerando-as como gêneros tão "sérios" (embora nem sempre sisudos) e consistentes para o fazer pedagógico quanto os demais, já presentes no cotidiano das salas de aula (MENDONÇA, 2010, p. 224).

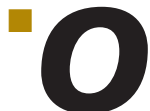

processo de ensino-aprendizagem de linguas estrangeiras no Brasil parece ter sofrido verdadeira homogeneização desde as décadas de 1960 e 1970, quando, no Brasil, as leis federais, promulgadas nesses anos, deixaram de incluir, como caráter obrigatório, a manutenção de uma 
lingua estrangeira nas escolas. Tal prerrogativa ficou relegada aos Conselhos Estaduais. Segundo Machado, Campos e Saunders (2007), é a partir desse hiato legalista que o inglês surge como uma língua hegemônica em um cenário pós Segunda Guerra Mundial, cujas influências cultural e financeira de países anglófonos, como os Estados Unidos da América, aparecem de maneira mais acentuada:

As LDBs de 1961 e de 1971 ignoram a importância das línguas estrangeiras ao deixar de inclui-las dentre as disciplinas obrigatórias: Português, Matemática, Geografia, História e Ciências. As duas LDBs deixaram a cargo dos Conselhos Estaduais decidir sobre o ensino de línguas. Desde então, cresce a opção pelo inglês e, nos últimos trinta anos, observa-se uma explosão de cursos particulares de inglês, com a intensificação do senso comum de que não se aprende língua estrangeira nas escolas regulares (MACHADO; CAMPOS; SAUNDERS, 2007).

Neste artigo, no entanto, interessa-nos destacar, inicialmente, o fato de que a visão singular de língua estrangeira, doravante LE, como currículo pode estar diretamente ligada a esses fatores históricos que mantêm diálogo preponderante com o contexto brasileiro atual, no qual ainda vivemos singularidades quando o assunto é aprender uma língua que não seja a materna.

Apesar disso, esforços para a pluralização dessa e outras visões mais acanhadas do ensino de LE não têm faltado, ao menos, é claro, no papel. Haja vista que os Parâmetros Curriculares Nacionais (PCN), na condição de documento oficial e mais abrangente, alertavam-nos a uma leitura criticista dessa tendência homogeneizante que acometeu grande parte, para não dizer a maioria, dos currículos brasileiros:

É verdade que o inglês predomina e a consciência crítica dessa situação deve ser considerada, mas há razoável quantidade do uso de outras línguas, tais como o italiano, o francês, o espanhol, o alemão, dependendo do contexto e das regiões. Essa quantidade de língua estrangeira tem de ser aproveitada, a fim de tornar significativo, porque concreto, algo que de outro modo nunca seria percebido como real, vivo, usado por milhões de seres humanos para se comunicar e conduzir a vida (BRASIL, 1998, p. 65).

De acordo com esse documento, o critério para escolha de uma LE no currículo de uma escola estaria condicionado à utilização e ligação dessa língua às comunidades em que as escolas, a priori, estivessem instaladas. No entanto, por variados fatores, essa prerrogativa tem sido colocada em segundo plano e, muitas vezes, negligenciada. A despeito dessa constatação, os caracteres humano, ideológico, social e de poder, inerentes a qualquer língua, são estimulados pelos PCN, como uma maneira de (re)aproveitar tais princípios no processo educativo de vários brasileiros. No entanto, a Lei de Diretrizes e Bases da Educação Nacional e, inclusive, a Base Nacional Comum Curricular (2017) já ratificam o inglês como lingua estrangeira oficial de ensino no país.

É nessa circunscrição de disputas territoriais que propomos discutir, nesta pesquisa, o ensino de língua italiana mediado pelo uso do livro didático, mas e, principalmente, interposto por uma linguagem que, de igual modo, tem sofrido verdadeiros achaques e resistências na escola, a saber: os quadrinhos. Segundo Silva (2013), na perspectiva cultural, currículo é poder e se esse assim o é, podemos dizer que este trabalho se inscreve numa perspectiva de (re)visitar os 
poderes estabelecidos pela instituição escola que, verticalmente, denega há anos a inserção de outras culturas, línguas, ideologias e linguagens visando à manutenção uníssona de um único polo de poder.

\section{CONSIDERAÇÕES TEÓRICAS}

\section{A linguagem dos quadrinhos}

Por se tratar de uma área de produção heterogênea e extremamente neonata nos estudos linguísticos, os quadrinhos têm sido discutidos e revisitados por diversos campos do conhecimento. Interessa-nos, para esta pesquisa, filiar nosso deslizar teórico no território da linguística. Primeiro porque, como propõe Barbieri (1994, 1998), asseveramos que os quadrinhos são, a priori, uma linguagem específica, que traz consigo algumas implicações:

O que queremos dizer quando falamos de linguagem do quadrinho? Pensamos no que queremos dizer quando falamos da linguagem das palavras, isto é, da língua que usamos todos os dias para falar, para escrever e para compreender os outros que falam e escrevem [...]. Quando esses signos são somente as palavras, a linguagem é a lingua italiana (o francês, o inglês e assim por diante). Guando esses signos são diferentes das palavras, temos outras linguagens, como a do cinema, a das imagens, a da música, a do quadrinho. Os signos do quadrinho são figuras desenhadas e palavras (BARBIERI, 1994, p. 5, tradução nossa) ${ }^{1}$.

Com efeito, percebemos a diferenciação proposta por Barbieri (1994) entre a linguagem das palavras (lingua) e aquela que é produzida pela ação humana como produto e processo, ao mesmo tempo, das diversas intervenções culturais, para as quais são construídos alguns sintagmas nominais: "linguagem do cinema", "linguagem da música" etc. Circunscrever este estudo na linguística é dizer que os quadrinhos, no âmbito da linguagem, constituem-se como um dos duplos objetos da linguística, pois, conforme discute Benveniste (1976), essa ciência possui um duplo objeto que não necessariamente se encontram distantes, mas com características especialmente marcadas e que corroboram para a manutenção dessa indissociabilidade:

Comecemos por observar que a linguística tem duplo objeto: é ciência da linguagem e ciência das línguas. Essa distinção, que nem sempre se faz, é necessária: a linguagem, faculdade humana, característica universal e imutável do homem, não é a mesma coisa que as línguas, sempre particulares e variáveis, nas quais se realiza. É das linguas que se ocupa o linguista e a linguística é em primeiro lugar a teoria das linguas. Dentro da perspectiva em que nos aqui colocamos, veremos que essas vias diferentes se entrelaçam com frequência e finalmente se confundem, pois os problemas infinitamente diversos das linguas têm em comum o fato de que, a certo grau de generalidade, põem sempre em questão a linguagem (BENVENISTE, 1976, p. 20).

\footnotetext{
"Che cosa vogliamo dire quando parliamo di 'linguaggio' del fumetto? Pensiamo a che cosa vogliamo dire quando parliamo del 'linguaggio delle parole', cioè della lingua che usiamo tutti i giorni per parlare, per scrivere e per comprendere gli altri che parlano e scrivono [...] Quando questi segni sono le parole, il linguaggio è la lingua italiana (o francese, o inglese e così via). Quando questi segni sono diversi dalle parole, abbiamo altri linguaggi, come quello del cinema, quello delle immagini, quello della musica, o come quello del fumetto. I segni del fumetto sono figure disegnate e parole".
} 
Dessa forma, ao dizer que os quadrinhos são signos indiciados por figuras e palavras, Barbieri (1994) assume a posição aproximativa que língua e linguagem têm para Benveniste (1976). São particularidades que se estreitam, delimitam-se e, paradoxalmente, aproximam-se a partir de uma linha tênue e quase imperceptivel. Língua e linguagem são objetos de estudos da linguística e os quadrinhos, por seu turno, também o são, porque conjugam figura e palavra à vista de um signo.

É importante, ainda, expor que, para Barbieri (1998), os quadrinhos mantêm, junto às demais linguagens, relações que se subdividem em quatro tipos, a saber: inclusão, geração, convergência e adequação. Somente a partir dessa discussão é que ele se arrisca a afirmar que, na comunicação instaurada pelos quadrinhos, existem constantes e inegáveis aproximações entre uma e outra linguagem preponderantemente marcada pela ação humana:

[...] a comunicação e um ambiente geral cujos subambientes, as linguagens, vivem tumultuosamente, distanciando-se, aproximando-se, intercambiando características, às vezes morrendo e outras dando vida a uma nova possibilidade expressiva (BARBIERI, 1998, p. 17, tradução nossa) ${ }^{2}$.

Nesse sentido, é possivel compreender que, para além de qualquer outra acepção, valemo-nos daquela que entende essa linguagem como produto e processo de ações humanas que dialogam com outras, mas não perde sua essência nem deixa de existir per si. De maneira análoga e, ao mesmo tempo, distanciada, Cagnin (1975, p. 25), apesar de afirmar que os quadrinhos são um tipo de literatura, diz que as histórias em quadrinhos são "um sistema narrativo formado por dois códigos gráficos: a imagem, obtida pelo desenho, e a linguagem escrita".

Parece-nos, portanto, que as ideias tácita e análoga que perpassam as contribuições de Barbieri (1994, 1998) e Cagnin (1975) consideram que os quadrinhos possuem duas vertentes macros e constitutivas: a imagem e a palavra. Para além das demais associações que podem ser feitas com outras linguagens, os ambientes que elas criam, para citar Barbieri (1998), sugerem verdadeiros diálogos e, no entanto, delimitam uma territorialidade para esta linguagem dos quadrinhos, que conjuga, segundo ele, desenhos, cor, técnica, caricatura, pintura, fotografia, grafismos, música, poesia, narração, teatro e animação (BARBIERI, 1998).

Cagnin (1975), à época, muito inclinado às questões que tangenciavam suas pesquisas, preocupa-se em aproximar as histórias em quadrinhos à temporalidade e à narrativa. Contudo, utiliza-se de considerações importantes para inaugurar, no Brasil, alguns percursos de análise e compreensão dessa linguagem. Para ele, imagem e texto são os constituintes basilares dos quadrinhos e se somam ao universo epistemológico que chamamos de linguística:

Aqui é fácil compreender a função de complementaridade dos dois sistemas envolvidos nas H.Q. O elemento linguístico tem um amplo poder de representação no vasto campo dos conceitos universais, mas o elemento icônico só traz diante de nós o simulacro dos objetos físicos e, no máximo, sugestões de movimento e sucessão. A imagem, no entanto, está revestida da imensa riqueza da representação do real com características individuais (CAGNIN, 1975, p. 30).

2 "[...] la comunicación es um ambiente general cuyos sub-ambientes, los linguajes, viven tumultuosamente, alejándose, acercándose, intercambiando características, a veces muriendo, y otras dando vida a uma nueva possibilidade expressiva". 
Esses sistemas, explicitados por Cagnin (1975), somam a questão visual ao verbal e nos permitem dizer que, ao entrarmos em contato com os quadrinhos, lidamos com uma linguagem específica e, de acordo com Ramos (2012), até autônoma. Nesse sentido, se interagimos com essas duas especificidades imbricadas, é razoável dizer que lemos quadrinhos e encontramos neles características importantes que nos permitem partir deles para realizarmos análises linguísticas:

Ler quadrinhos é ler sua linguagem. Dominá-las, mesmo que em seus conceitos mais básicos, é condição para a plena compreensão da história e para a aplicação dos quadrinhos em sala de aula e em pesquisas científicas sobre o assunto (RAMOS, 2012, p. 30).

Dessa maneira, para compreender e pesquisar os quadrinhos, é preciso, primeiro, tomá-los como uma linguagem constitutiva, mas que agrega, simultaneamente, as demais existentes em nossa sociedade e, além disso, considerá-los verdadeiras expressões humanas, já datadas há muito, que reclamam espaço de reconhecimento, compreensão e pesquisas sérias. Sendo, portanto, necessária a análise o mais distante possivel dos achaques e estigmas aos quais têm sido submetidos ao longo de sua existência. Para tanto, é imprescindível que se relacionem elementos analíticos coesos, como a questão genérica ${ }^{3}$ - tão problemática em diversos estudos linguísticos - das representações da palavra, ou seja, do texto verbal, da visualidade e, finalmente, do espaço-temporal que cerceia os quadrinhos de maneira singular.

\section{Os quadrinhos na linguagem: contextos educacionais e de ensino de línguas}

Consideramos anteriormente que os quadrinhos constituem uma linguagem e, como tal, essa também é uma das preocupações no ensino-aprendizagem de línguas. Quando ensinamos línguas, não deixamos de ensinar linguagem. Novamente, defrontamo-nos com o caminho biarticulado que Benveniste (1976, 2006) afirma ter os estudos linguísticos. Esse mesmo estudioso, ao tratar de questões de lingua e de linguagem, discute a enunciação como um construto importante para que a lingua entre em funcionamento por meio de um ato individualizado:

A enunciação é este colocar em funcionamento a língua por um ato individual de utilização [...] É preciso ter cuidado com a condição específica da enunciação: é o ato mesmo de produzir um enunciado, e não o texto do enunciado, que é nosso objeto. Este ato é o fato do locutor que mobiliza a língua por sua conta (BENVENISTE, 2006, p. 82).

Ora, se o ato individual confere forma à lingua e essa, por sua vez, comporta a linguagem como uma faculdade humana, podemos dizer que, ao ensinarmos língua, estamos diante de atos de linguagem. O silogismo, aqui aplicado, na verdade, reivindica o suporte em várias discussões sobre a aprendizagem de línguas que têm sido realizadas no Brasil e alhures. Referimo-nos às contribuições de Leontiev (1984) e Dolz, Pasquier e Bronckart (1993), que tratam da atividade/ação de linguagem como um nascedouro das interações sociais:

\footnotetext{
3 No sentido de gênero do discurso.
} 
Dentre as diferentes atividades humanas, a atividade de linguagem funciona como uma interface entre o sujeito e o meio e responde a um motivo geral de representação-comunicação. Ela sempre tem sua origem nas situações de comunicação, desenvolve-se em zonas de cooperação social determinadas e, sobretudo, ela atribui às práticas sociais um papel determinante na explicação de seu funcionamento (SCHNEUWLY; DOLZ, 2004, p. 63).

Como vimos, há uma forte imbricação entre o ato individual de linguagem que produz funcionamento na lingua, a enunciação, cunhada por Benveniste (2006), e as atividades / ações de linguagem discutidas por Schneuwly e Dolz (2004). Nesse cenário, estamos considerando que os quadrinhos, como tais, também são uma prática social e, consequentemente, uma prática de linguagem que pode e deve adentrar ao universo escolar, uma vez que as atividades de linguagem têm origem nas situações de comunicações sociais.

Sendo os quadrinhos uma prática social e de linguagem, fica difícil entender como e por que o solipsismo imposto a eles, que são parte alijada na educação, ainda persiste em durar no ensino de línguas. Ao depararmo-nos com essa linguagem em processos educativos, observamos, quando muito, que são incluídos como recursos segundos ou com uma faixa etária datada: tão somente as crianças. A esse respeito, Mendonça (2010, p. 209) alerta-nos:

A alegada "crise de leitura" entre jovens e crianças já vem sendo questionada há algum tempo. Afirmações do tipo "o jovem não lê" não encontram respaldo empírico, quando se trata de determinados objetos de leitura. É fato incontestável que jovens leitores (nem tão jovens assim) deleitam-se com as tramas narrativas de personagens diversos, heróis ou anti-heróis, montadas através do recurso de quadrinização.

Portanto, ensinar língua e linguagem está para além do enunciado stricto sensu, mas envolve processos mais complexos que abarcam as práticas sociais e comunicativas, das quais os usuários e aprendizes de uma lingua não estão imunes, o que sugere a necessidade de trazer para a escola a interação que ocorre para além de seus muros. A nosso ver, os quadrinhos podem e devem ser uma alternativa interessante quando lidamos, especialmente, com o ensino de língua estrangeira e de suas especificidades.

\section{Ensinar e aprender italiano como língua estrangeira: o livro como um recurso}

Com efeito, ensinar-aprender é um binômio indissociável das relações humanas em que as interações se fazem necessárias. O fato é que, na maioria das vezes, principalmente na condição de professores, parece que separamos essas duas facetas de nossas ações pedagógicas e passamos a investir em apenas uma delas: ensinar, por exemplo. Se assim o fazemos, no que diz respeito ao ensino-aprendizagem de línguas, especialmente o de língua estrangeira, cindimos processos importantes de nossa condição de aprendizes. Daí, talvez, resultem os inúmeros insucessos do ensino de língua estrangeira em espaços de educação pública, pois passamos a desconsiderar que aprender uma língua é também e, principalmente, depreender sua cultura nos aspectos mais latentes: 
Lingua e cultura tornam-se, assim, um binômio indissolúvel para o linguista aplicado e para o professor de línguas: a língua é veículo e, ao mesmo tempo, manifestação de cultura pela qual a aquisição de uma língua comporta a assimilação também dos tratos culturais próprios da sociedade que usa a língua (PICHIASSI, 1999, p. 23, tradução nossa) ${ }^{4}$.

É possivel perceber que, para Pichiassi (1999), aprender uma língua é passar do mundo da superficialidade para algo mais amplo. É, nesse sentido, resgatar e incorporar elementos da cultura para a sala de aula, de modo a torná-los, cada vez mais, integrantes de um mundo enclausurado, como é o da escola. Ora, se é culturalmente requisitado que, no mundo globalizado, o aluno tenha acesso a um sem fim de conhecimentos que o ajude a (sobre)viver nesse contexto global, é de se esperar, de igual modo, que as aprendizagens de outras linguas, que não a sua materna, suscitem essa inserção ampliada de um sujeito, cada vez menos, local, conferindo-lhe, é claro, novas possibilidades de diálogos com outras inúmeras instâncias de poder.

Outrossim, é-nos imperativo destacar que o ensino de línguas se apresenta para o professor e para o pesquisador de maneira multifacetada, o que nos permite dizer que uma taxionomia desses diversos ensinos é latente e necessária para dirigir os estudos que aqui se seguem. Dessa forma, de acordo com Pichiassi (1999), ao ensinarmos linguas, podemos estar centrados em um ensino de lingua: materna, nacional, estrangeira, segunda (L2), primeira (L1), étnica, minoritária ou clássica. Interessa-nos, nesta pesquisa, destacar e filiar-nos à perspectiva de que o italiano, no Brasil, se dá pelo ensino de língua estrangeira, porque "é a língua não presente no território no qual ela é ensinada/aprendida; por exemplo, o inglês na Itália ou o italiano na Inglaterra" (PICHIASSI, 1999, p. 17, tradução nossa) ${ }^{5}$.

Nesse sentido, para que o ensino de lingua estrangeira ocorra, alguns processos e meandros precisam se desenrolar, de modo que satisfaça uma axiologia criada em diversos espaços públicos ou privados em que ele se dá:

No processo de ensino de línguas, podem-se individualizar um sujeito, um objeto, uma situação e alguns meios: o aluno (aprendiz) e, em alguns aspectos, também o professor é o sujeito do mesmo processo, a língua é o objeto, a situação é o contexto sociocultural no qual os protagonistas atuam e, finalmente, o método $e$ as estratégias colocadas no ato do professor e do aluno para chegar a posse de uma língua constituem os meios (PICHIASSI, 1999, p. 17, tradução nossa) ${ }^{6}$.

Ao analisarmos esse excerto, percebemos que, para além da língua propriamente dita, outros aspectos interagem na sua concretização e aprendizagem eficaz. Um dos destaques que fazemos, em especial neste trabalho, é o do método e, consequentemente, das estratégias utilizadas para atingir essa finalidade tão complexa, que é o de aprender e, ao mesmo tempo, ensinar uma língua estrangeira. Para nós, no entanto, importa o destaque ao método e às estratégias,

4 "Lingua e cultura sono diventati così un binomio indissolubile per il glottodidatta e per l'insegnante di lingue: la lingua è veicolo e allo stesso tempo manifestazione di cultura, per cui l'acquisizione di una lingua comporta l'assimilazione anche dei tratti culturali propri della società che usa la lingua".

5 "[...] è la língua non presente nel territorio in cui essa è insegnatalappresa; ad. es., l'inglese in Italia o l'italiano in Inghilterra".

6 "Nel processo glottodidattico si possono individuare um soggetto, un oggetto, una situazione e dei mezzi: l'allievo (apprendente) e, per certi versi, anche l'insegnante è il sogetto del processo stesso, la lingua è l'oggetto, la situazione è il contesto socioculturale in cui i protagonisti operano, ed infine, il metodo e le strategie messe in atto dall'insegnante e dall'allievo per arrivare al possesso di una lingua costituiscono i mezzi". 
pois entendemos o primeiro como a abordagem que suporta as ações de aprendizagem de uma língua estrangeira e, as estratégias, como aquelas que reúnem alcances tangiveis e delineados nesse processo. Tomamos o livro didático, constituinte como corpus de nossa pesquisa, como uma estratégia que remete a uma abordagem ou método comunicativo porque:

Fala-se, ainda nos primeiros tempos, de métodos que se inspiram na abordagem comunicativa, mas em alguns pressupostos da abordagem comunicativa que põem os discentes e suas necessidades comunicativas no centro do processo, a atenção ao "saber fazer" em língua [...] (PICHIASSI, 1999, p. 141, tradução nossa) ${ }^{7}$.

Dessa forma, parece-nos coerente dizer que, dentro de uma abordagem comunicativa, temos uma propositura de estratégia (material) que se coaduna a ela, em que o livro didático, que ora analisamos, apresenta-se como um recurso para aprendizagem dessa lingua e, por isso, também se constitui como um dos importantes elementos que se instaura no processo supracitado. Entretanto, Borneto (1998, p. 155, tradução nossa) adverte-nos para a seguinte tratativa:

Parece-nos, por experiência pessoal, que uma das maiores dificuldades para um jovem professor no início do próprio percurso profissional consista no conhecimento e na escolha do material a ser usado em aula. O mercado editorial oferece uma ampla variedade de propostas para a didática, algumas das quais também muito válidas e interessantes, e a solução mais fácil poderia aparecer, sem dúvida, como aquela que adota uma proposta e a segue in toto ${ }^{8}$.

Estamos, portanto, diante de um trabalho que consegue reunir, no bojo de suas fundamentações e procedimentos de análise, verdadeiros desafios do ponto de vista de uma tentativa de conjugar, ao mesmo tempo, uma linguagem historicamente preterida na escola e uma língua estrangeira que foge ao lugar comum do currículo cristalizado e, nesse entrecruzamento, propõe analisar um recurso material que pode auxiliar professores de lingua italiana na escolha e análise crítica, por exemplo, dos livros disponiveis no mercado editorial, a fim de que as aulas, destinadas a aprender língua e quadrinhos, se deem da maneira mais adequada possivel.

\section{ENSINAR LÍNGUA ESTRANGEIRA COM O LIVRO DIDÁTICO: UMA ANÁLISE DOS QUADRINHOS}

\section{Primeiras palavras: Por que os quadrinhos?}

O nome projeto editorial diz muito sobre o material analisado e, principalmente, sobre por que, supostamente, os quadrinhos seriam uma maneira de aproximação deste ou daquele grupo da sociedade - vide o adjetivo junior ${ }^{9}$ na capa, que, em lingua inglesa, recupera a ideia de filho ou mais novo hierarquicamente. Nes-

\footnotetext{
7 "Si parla ancora, nei primi tempi, di metodi che si ispirano all'approccio comunicativo, ma certi pressuposti dell'approccio comunicativo che pongono il discente e i suoi bisogni comunicativi al centro del processo, l'attenzione al 'saper fare' in lingua [...]".

8 "Ci sembra per esperienza personale che uma delle maggiori difficoltà per un giovane insegnanti agli inizi del proprio percorso professionale consista nella conoscenza e nella scelta del materiale da usare in classe. Il mercato editoriale offre certo un'ampia varietà di proposte per la didattica, alcune delle quali anche molto valide ed interessanti, e la soluzione più facile potrebbe apparire senz'altro quella di adottare una di quelle proposte e seguirla in toto".

9 Conforme Kernerman (2005).
} 
se caso, temos um livro didático autointitulado Progetto (projeto) de ensino de italiano para os mais novos, especificamente os adolescentes. Embora a capa não seja, necessariamente, objeto de nossa análise, ela se configura como uma porta de entrada que, a priori, dialogaria com essa faixa etária de maneira mais visual.

Uma segunda informação constante nesse espaço verbal e visual, por nós denominada capa, consegue responder, de maneira mais satisfatória, à pergunta que lançamos nesta subseção do artigo: os quadrinhos são usados no material didático porque seriam a linguagem mais lida, acessada e conhecida dos adolescentes. Observe que o subtítulo do livro é inscrito da seguinte maneira: "Corso multimediale di italiano per adolescenti" ${ }^{10}$. Ademais, saltam-nos aos olhos as imagens de supostas pessoas que se assemelhem àquelas dessa idade, com práticas sociais próprias desse momento da vida: amizade, namoro e, é claro, poses para fotos.

Figura 1 - Capa do livro

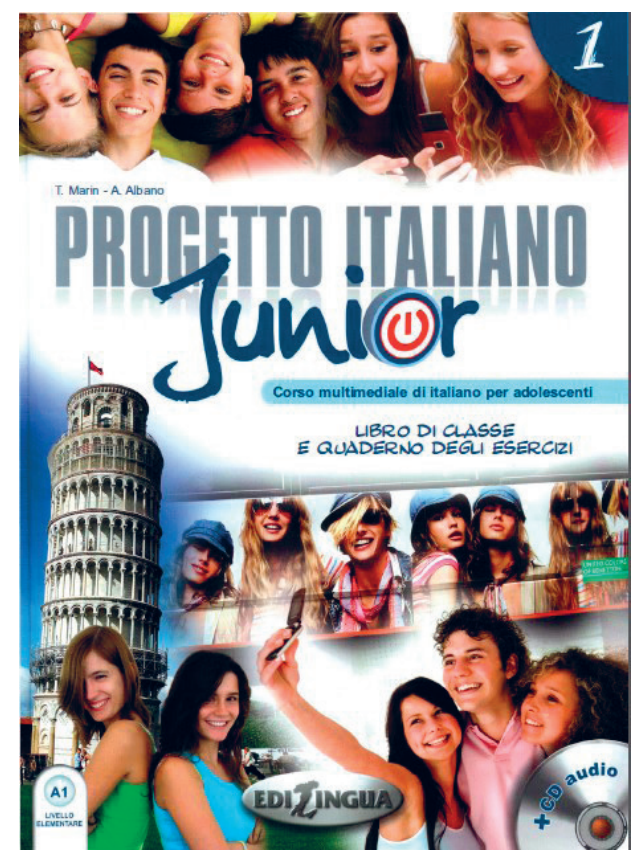

Fonte: Albano e Marin (2014).

Em consonância com o enunciado da capa, também nas primeiras páginas do livro, percebemos uma explicação que responde por que os quadrinhos e com quais finalidades eles serão utilizados. De modo que, a "Premissa", indicada por título dessa introdução, reúne dados sobre como trabalharam os editores/autores e a filosofia à qual o livro se filia para atingir os objetivos por eles propostos:

Uma escolha fundamental foi a de inventar uma história em quadrinhos, que percorre todas as 18 unidades didáticas do curso, e que apresenta cinco protagonistas, garotos e garotas, personagens completos com os quais os alunos

10 "Curso multimídia de italiano para adolescentes" (tradução nossa). 
podem se identificar. Personagens que têm seus mesmos interesses, passam pelos mesmos problemas, vivem com as suas mesmas ansiedades e experiências, usam uma linguagem juvenil. Tudo isso com realismo e a necessária dose de humor (ALBANO; MARIN, 2014, p. 3, tradução nossa) ${ }^{11}$.

Percebemos que a associação do material didático com os quadrinhos parece se dar porque, na visão dos editores, os quadrinhos seriam, na essência, uma linguagem para o público juvenil, acrescida da ideia preliminar de que eles trabalham, prioritariamente, com o humor. Sabemos, no entanto, que essa visão tacanha, em nossa avaliação, cerceia o espaço tangencial dos quadrinhos na relação humana: eles não são exclusividades de uma faixa etária e nem sempre se balizam no humor para se constituir. Entretanto, o que conseguimos analisar, no excerto anterior, é essa tentativa de (re)validar, em principio, o que se sabe de maneira genérica sobre os quadrinhos, sem ao menos, dar voz a outras possibilidades: por que essa linguagem não poderia ser utilizada para outras faixas etárias? Apenas adolescentes e crianças leem quadrinhos? Eles devem ser humorísticos? As respostas a essas perguntas sugerem outro trabalho como este, mas podem ser, rapidamente, dadas ao entrarmos em contato com esse universo e percebermos que, da criança ao adulto, é possivel encontrar amostras dessa linguagem, com e sem qualidades, mas que predomina, de fato, entre os leitores mais jovens.

Nesse mesmo trecho, lemos que a história que atravessa o livro por inteiro é constituída por um quadro fixo de personagens, com características psicossociais parecidas às do público-alvo do material didático. Um detalhe chama-nos a atenção: a história em quadrinhos foi inventada para uma finalidade de ensino específico. O exíguo espaço deste estudo não nos permite aprofundar nesta problemática, mas não poderíamos deixar de observar essa constatação, pois ela está fortemente imbricada com o que expusemos em nossas considerações teóricas a respeito da transposição didática.

Por fim, transpor um conteúdo, que, para nós, é materializado em texto/gênero do discurso, deve ser uma atividade controlada, conforme alerta Lerner (2002). Isso porque, a nosso ver, o gênero do discurso, deve circular numa sociedade para se tornar objeto de ensino e, consequentemente, de transposição didática. A invenção de uma história em quadrinhos com a finalidade didática pode sugerir superficialidade às práticas interativas dentro de sala de aula, além de revelar uma ruptura social de circulação desse conteúdo como realidade e ato de linguagem, para citarmos Schneuwly e Dolz (2004). Apesar dessa constatação, a verossimilhança e aproximação da história, criada pelos autores do livro didático, com as que circulam na sociedade, serviram, também, de análise neste artigo.

\section{Segundas palavras: como os quadrinhos atuam e são utilizados no ensino de italiano?}

\section{Arena dissonante: Bem-vindos!}

O primeiro quadrinho que aparece no livro não está ligado à história que perpassa o material porque está localizado na parte introdutória, a qual prevê

\footnotetext{
11 Una scelta fondamentale è stata quella di inventare una storia a fumetti, che percorre tutte le 18 unità didattiche del corso, e che vede cinque protagonisti, ragazzi e ragazze, personaggi completi con cui gli studenti si possono identificare. Personaggi che hanno gli stessi loro interessi, affrontano gli stessi problemi, vivono le loro stesse ansie ed esperienze, usano un linguaggio giovanile. II tutto visto con realismo e la necessaria dose di umorismo.
} 
um panorama sobre alguns aspectos essenciais de desenvolvimento durante a proposta do curso: características fonológicas, morfológicas, culturais, e, principalmente, interativas. Remontando elementos da linguagem dos quadrinhos, eles surgem com a representação de uma sala de aula, em que os alunos falam e recorrem a diversas orações típicas desse contexto:

Figura 2 - Primeiro quadrinho: benvenuti

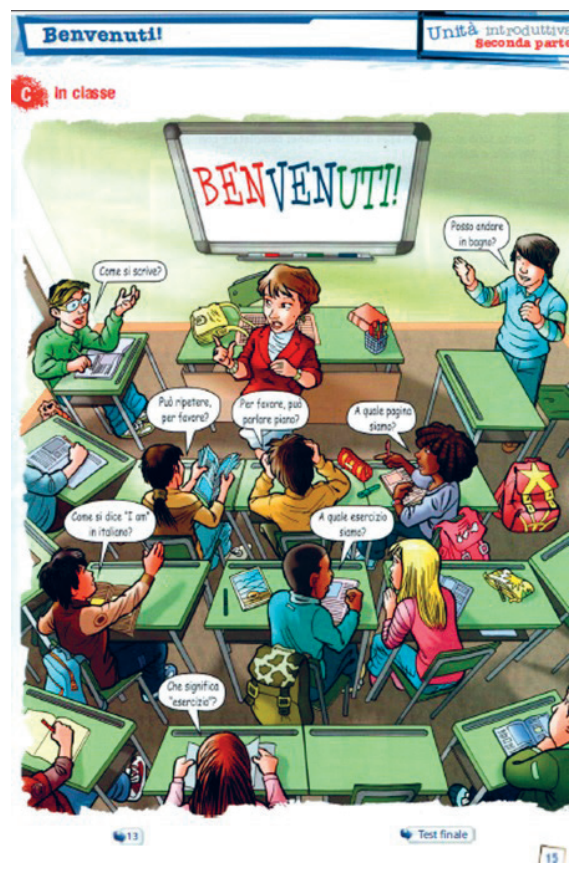

Fonte: Albano e Marin (2014).

Segundo Ramos (2012), os balões constituem uma das características dos quadrinhos que mais os aproximam do que, para nós, pode ser uma linguagem constitutiva. Nessa imagem, embora não tenhamos a divisão clássica dos quadros, podemos afirmar que se trata de quadrinhos não porque possui balões, mas porque reúne outros elementos característicos dessa linguagem: a imagem, o espaço-tempo e a narratividade como tipologia textual inerente a esse hipergênero ${ }^{12}$.

Contudo, ao nos depararmos com essa representação da aula (In classe), a primeira inferência que nos ocorre é aquela em que ninguém presta atenção à professora e a segunda é de que todos falam ao mesmo tempo, de modo a criar um problema para o leitor, que, neste caso, não sabe quem começa e termina a fala, além de sugerir, pela expressão da professora, que ela também não sabe o que fazer, afinal são muitas perguntas. Apenas uma dupla conversa entre si, de modo que as demais perguntas são dirigidas à professora, que está na frente da sala e, mesmo assim, não sabe por onde começar.

Por ser verossímil, é possível dizer que situações, como essa explicitada nos quadrinhos, são validadas na medida em que encontra contiguidade na realidade:

12 Com base em Ramos (2012), consideramos os quadrinhos como um hipergênero que agrega e converge outros diferentes gêneros. 
não raramente, os professores se veem enredados por uma arena de vozes, com a qual é obrigado a lidar. Sabemos, no entanto, que se trata de uma aula inaugural, uma vez que o "Benvenuti!"13, sugestivamente colorido com as cores da bandeira da Itália, revela esse aspecto de início. Aqui, percebemos claramente que o objetivo principal do uso do quadrinho é apresentar aos usuários do material didático quais expressões ele deve e pode usar durante a aula para interagir com os colegas e com a professora. É interessante que muitas dessas expressões preveem o uso inequívoco do livro na sala: "A quale pagina siamo?"14 ou "che significa esercizio?"15.

\section{O primeiro contato: "escutar os quadrinhos"}

O segundo quadrinho, que é utilizado no livro para introduzir uma situação de comunicação, reapresenta mais elementos constitutivos dessa linguagem. Notadamente, a separação por vinhetas, enquadramentos diversos, temporalidade e ações múltiplas aproximam a história inventada ${ }^{16}$ aos clássicos "quadrinhos". Nele, é iniciado o programa de diálogos e situações comunicativas que se desvelam e se amadurecem ao longo do livro.

Trata-se do primeiro dia de Chiara na escola. Ela encontra Alessia e ambas iniciam uma interação conversacional, que se desenrola para a apresentação do novo espaço à recém-chegada e aos colegas de turma. Além disso, o tópico conversacional se desenvolve a partir do mote de introdução/apresentação das pessoas, explorando, principalmente, o local onde mora, como se locomove, família e amigos.

Figura 3 - Segundo quadrinho: apresentação

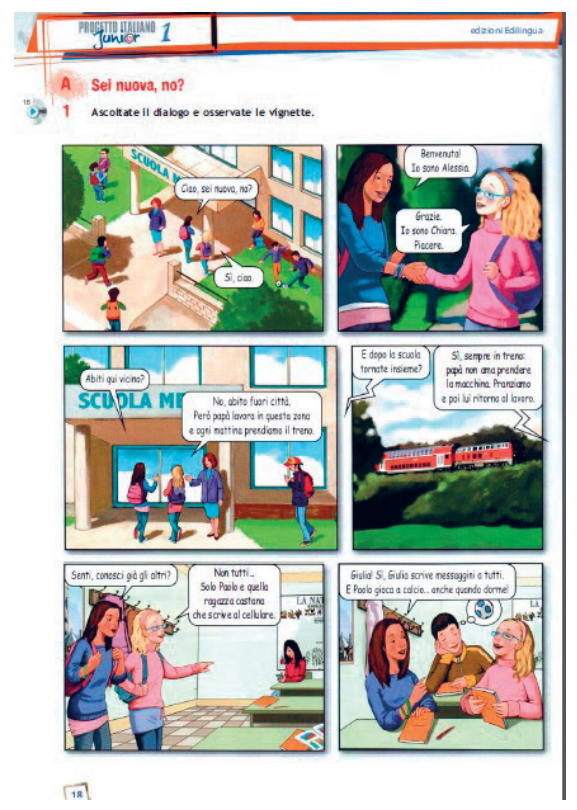

\footnotetext{
13 "Bem-vindos" (tradução nossa).

14 "Em que página estamos?" (tradução nossa).

15 "O que significa exercício?" (tradução nossa).

16 Termo utilizado pelos próprios autores/editores.
} 
Vemos, ineditamente, um enunciado que emprega a tipologia injuntiva para o desenvolvimento de uma das habilidades, segundo Brasil (1998), requeridas para o trabalho com ensino de língua estrangeira: escutar. Deparamo-nos com a seguinte direção: "Ascoltate e osservate le vignette"17. Entendemos a solicitação de observação como aquela que indica a leitura como uma atividade segunda, quando o principal objetivo é escutar. Como se trata de um curso multimídia, ele é acompanhado de um $\mathrm{CD}$ e, ao lado da injunção, encontramos um símbolo gráfico que indica o número da faixa.

Partindo para os quadrinhos propriamente ditos, deparamo-nos com um enquadramento, segundo Ramos (2012, p. 143), de visão superior: "de cima para baixo". Apesar disso, a presença da representação da fala e de um diálogo aparece no primeiro quadro. Parece-nos que, com esse foco, o objetivo é mostrar que os que conversam se encontram em uma escola (scuola media). Esse primeiro enquadramento é importante porque dirá muito ao leitor sobre as condições espaço-temporais em que se dará a interação ao longo da história. Percebemos aí uma forte imbricação do texto escrito com o visual, uma vez que os dois convergem para situar o enunciatário no contexto do diálogo que se desenrolará. Caso estivéssemos, talvez, em outro material, o leitor precisaria saber, antecipadamente, que o diálogo se daria numa escola.

O recorte tempo-espacial, que se dá entre a leitura do primeiro quadro e do segundo, é notório, principalmente, pela ação da escolha do plano. Passa-se de "visão superior" para, segundo Ramos (2012), um plano médio ou aproximado, o qual coloca em evidência o diálogo introdutório entre as duas personagens, de maneira a suscitar a aprendizagem de expressões de saudação.

O terceiro quadro dessa história irrompe à medida que Alessia e Chiara continuam a conversa ao entrarem na escola. Nesse momento, falas como "Abiti qui vicino?"18 e "No, abito fuori città"19 sugerem certa proximidade entre as duas e, ao mesmo tempo, introduzem a compreensão da próxima vinheta. Os leitores / alunos só saberão que são elas que continuam conversando pela presença de dois balões no topo do quadro e mantendo o mesmo tópico que foi iniciado anteriormente: onde mora, como se locomove etc. É recorrente a mudança na forma do apêndice dos balões ${ }^{20}$, o qual aparece um pouco trêmulo para mostrar que os que dialogavam no quadro anterior são os mesmos que continuam falando neste. Aliás, esse recurso é repetido em outras situações de comunicação. Parece-nos, portanto, que o objetivo de tirar de cena as personagens é trabalhar com o vocabulário próprio ao universo do transporte: treno ${ }^{21}$, por exemplo.

Por fim, os dois últimos quadros são os terminativos da situação de comunicação proposta, pois Alessia e Chiara já estão dentro da escola e a primeira apresenta à segunda alguns colegas de turma, bem como os traços psicossociais deles, a fim de dar continuidade ao fio narrativo que conduz a história no livro.

Dessa maneira, é possivel asseverar que, nesta primeira análise, conforme declara Pichiassi (1999), ensinar lingua é, também, ensinar cultura na medida em que futebol, escola, meio de transporte, morar fora da cidade e o uso exces-

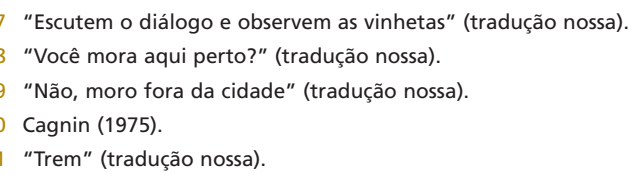


sivo do celular pelos mais jovens podem ser indícios de aprendizagem na língua e para além dela. É-nos mostrado, de igual modo, que ler quadrinhos, ainda que em língua estrangeira, é ler os meandros de sua linguagem. Aqui, vemos, de maneira conjugada, o trabalho com a habilidade de escuta - primordialmente somada à de leitura.

\section{Ler o espaço-tempo dos quadrinhos}

$\mathrm{Na}$ continuidade da história apresentada durante a utilização do livro, deparamo-nos com a introdução de novos elementos na narração. Não obstante a essa constatação, percebemos que, na página 23, Chiara, a aluna nova, conhece mais um integrante da turma, Paolo, e, além disso, conta um pouco mais sobre sua vida, trajetos de ida e volta da escola e sobre sua familia. Contudo, percebemos nessa situação de comunicação que a atividade, introduzida pelo enunciado injuntivo "Lavorate in coppia. Cercate di mettere in ordine le vignette. Riascoltate per verificare" 22 , sugere uma preocupação, ainda com a leitura, mas, principalmente, com um dos aspectos característicos das histórias em quadrinhos: o da narração.

Figura 4 - Quadrinhos e narração

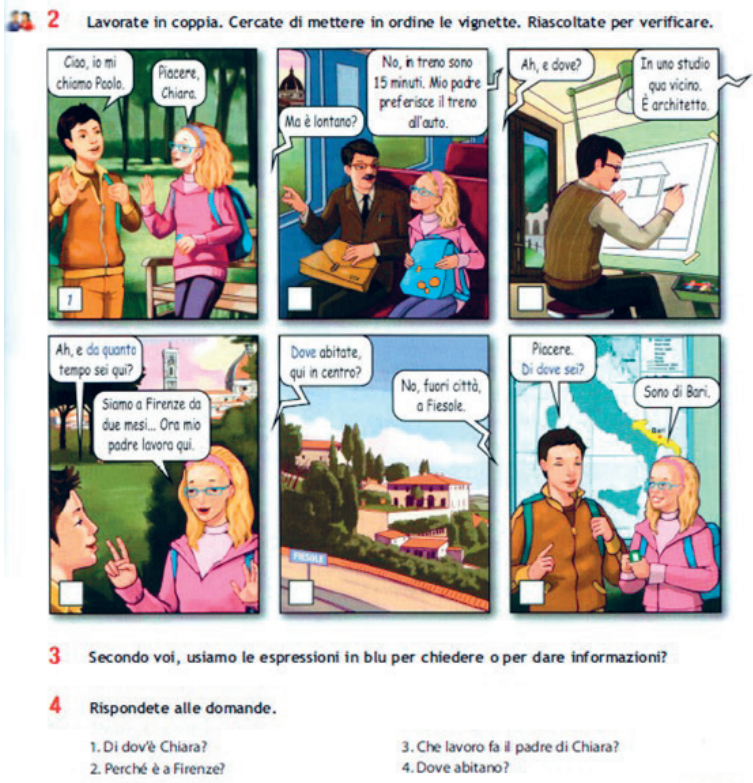

Nessa atividade, os alunos, inicialmente, são introduzidos a mais um capitulo da história, ao mesmo tempo em que são desafiados a compreender e a ler os quadrinhos a partir de uma característica também importante dessa linguagem: a narração. Vemos que os quadrinhos estão fora de ordem e, por isso, parece-nos 
que, para reordená-los, eles precisarão ler a parte verbal do texto, materializada no diálogo, além de ler a parte visual: as imagens, uma vez que, por se tratar de uma unidade inicial, caso encontrem dificuldades com o italiano, podem se valer da visualidade para conferir sentido e ordenar o diálogo. As atividades que se seguem visam a, respectivamente, ensinar expressões para pedir e dar informações e localizar dados no texto. Finalmente, notamos que os apêndices dos balões reaparecem de maneira trêmula, pois saem de cena as personagens que falavam no quadro anterior, mas que permanecem falando no quadro sucessivo, apesar de não aparecerem.

\section{Os quadrinhos para ensinar a escrever ou a copiar?}

Há uma confusão muito grande quanto às proposições de atividades com vistas ao trabalho com as habilidades requeridas por documentos institucionais, tanto fora como dentro do Brasil. Essa pressão, que ocorre externamente, (re)aparece na atividade em que os quadrinhos de nosso corpus são utilizados como pretexto para que o aluno apenas complete frases e orações nos diálogos. Mecanismo muito usual nos livros de ensino de língua estrangeira, ele também se apresentou latente, mesmo usando uma linguagem com características que, a priori, parecem refutar tais práticas.

Figura 5 - Copiar orações

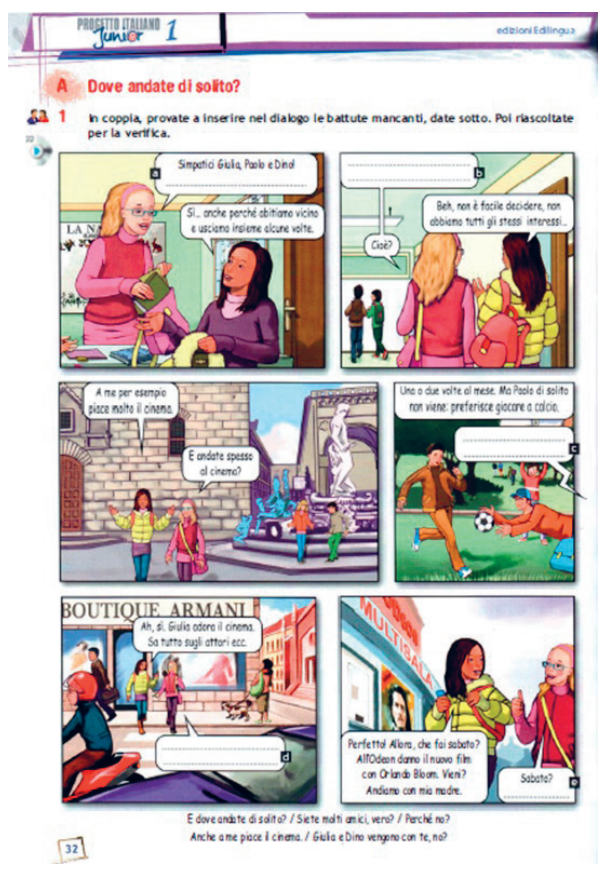

Nesses quadrinhos, a preocupação inicial da atividade proposta é ensinar o aluno a escrever; todavia, o privilégio da habilidade de leitura prevalece na medida em que ele é desafiado a preencher as lacunas tracejadas em branco com as orações que faltam no diálogo, as quais são dadas, conforme explica e pede o 
enunciado, abaixo da história. O fato de elas estarem dispostas no final da página obriga o aluno a fazer uma leitura rápida das imagens antes de procurar e preencher o que falta. Entretanto, como já mencionado, a leitura prevalece, já que o exercício é realizado com uma cópia e não ligado a uma produção textual. Além disso, o resgate da escuta é, mais uma vez, necessário para verificar se o que se completou está correto.

Por fim, nesse trecho da história os lugares e as paisagens, tipicamente citadinas e italianas, remontam aspectos culturais que, novamente, conjugam e reafirmam a indissociabilidade de que aprender uma lingua é, também, aprender sua cultura.

\section{CONSIDERAÇÕES FINAIS}

A linguagem dos quadrinhos tem sido objeto de numerosos estudos direcionados a várias áreas do conhecimento. Neste artigo, estamos alicerçados nas contribuições advindas dos estudos linguísticos e, em especial, das pesquisas que envolvem preocupações com o ensino de língua estrangeira fora e dentro do Brasil. Nesse sentido, é possivel depreender que este trabalho, embora careça de olhares mais apurados, é um prospecto inicial de que as análises que envolvem quadrinhos e ensino de LE ainda têm muito a revelar e a contribuir para esse campo de atuação singularmente difuso.

Posto isso, entendemos que as análises aqui realizadas dos quadrinhos e de seus usos no ensino de italiano alcançaram os objetivos propostos, porque somaram forças a partir de estudos precursores dessa linguagem àqueles que se atêm a um viés mais educativo. Dessa forma, à luz de pressupostos teóricos que inserem descrições analíticas, conseguimos elucidar estratégias utilizadas no livro didático a fim de estabelecer uma ligação de ensino-aprendizagem.

Outrossim, é preciso evidenciar que as hipóteses, elencadas em nossas considerações iniciais, foram parcialmente validadas na medida em que a primeira dizia respeito à aproximação, realizada pelos autores/editores do livro didático, da linguagem dos quadrinhos com a justificativa de que essa seria uma maneira de entrar no universo de um público específico: os adolescentes. Apesar de essa estratégia não estar, necessariamente, equivocada e ser entendida, por nós, como um ponto positivo do material didático, é preciso fazer uma leitura crítica de que essa suposta tentativa de acostar-se aos quadrinhos para atingir uma faixa etária revela o que, há muito, tem sido dito sobre eles: quadrinhos são para crianças. Nosso ponto crítico, no entanto, deixa essa discussão para estudos vindouros.

A segunda hipótese estava diretamente ligada à possibilidade de os quadrinhos estarem relacionados com o trabalho que se faz das habilidades requeridas e desejadas no ensino de LE: ler, escutar, falar e escrever. Como vimos, essa linguagem foi utilizada com vistas a estabelecer um ou outro diálogo estratégico com essas finalidades. Por vezes, elas se misturavam em um único exercício, porém mantendo uma em evidência. Percebemos, neste ponto, que a habilidade mais trabalhada com os quadrinhos foi a leitura e, em outro extremo, aquela que não foi alvo de preocupação dos editores, a fala. Parece-nos, portanto, que os quadrinhos podem ter uma contribuição significativa no ensino de LE, especialmente quando a preocupação estiver relacionada com a leitura. 
É preciso dizer que, apesar dessa preocupação com as questões que margeiam a aprendizagem de uma LE, não houve preocupação em se ensinar o aluno a ler os quadrinhos e seus meandros. Isso se deu porque, por força dos próprios recursos da linguagem, os alunos deveriam acionar o conhecimento prévio para mobilizar estratégias e compreender esta ou aquela proposta de exercício.

Ademais, do ponto de vista didático, é particularmente preocupante o fato de os quadrinhos utilizados como objeto de ensino-aprendizagem não circularem na sociedade. Entendemos que esse fator rompe com o processo de atividade de linguagem, que insere os verbos ensinar e aprender numa perspectiva de prática social. Apesar disso, o esforço de verossimilhança, em nossa avaliação, foi validado de maneira satisfatória, pois a história em quadrinhos, inventada para esse fim, reúne elementos importantes e característicos dessa linguagem.

Por fim, entendemos que esta pesquisa ainda está em processo devir porque os resultados aqui obtidos podem e devem ser analisados por outros vieses de conhecimento, a fim de tornar este estudo possivel de outras contribuições e olhares díspares do que foi empregado. Além disso, esperamos que os quadrinhos, assim como o ensino de outras linguas estrangeiras modernas, tornem-se objetos de estudos da academia e, assim, consigamos melhorar esse diálogo entre os quadrinhos, como prática social relevante, e a escola.

\section{Comics IN THE TEXTbOOK AND TEACHING-LEARNING OF ItALIAN LANGUAGE}

Abstract: This work aims to analyze the comics and their contributions to the teaching of the Italian language. For this, we selected, as corpus, the first volume of the Progetto Italiano Junior collection. It is interesting to know how the comics are used in this book and to what extent this language, which is exploited by it, is consistent with an efficient teaching of the target language through them. We are interested in the studies of Barbieri (1998), Cagnin (1975) and Ramos (2012), in order to discuss comics as a language, besides supporting Brazil (1998), Borneto (1998) and Pichiassi (1999) to discuss the Italian language in a teaching-learning context.

Keywords: Comics. Italian. Textbook.

\section{REFERÊNCIAS}

ALBANO, A.; MARIN, T. Progetto Italiano Junior. Roma: Edilingua, 2014.

BARBIERI, D. Il fumetto: volume antologico per la scuola. 1994. Disponivel em: http://www.danielebarbieri.it/texts/ilfumetto.pdf. Acesso em: $1^{\circ}$ abr. 2019.

BARBIERI, D. Los lenguajes del cómic. Barcelona: Paidós, 1998.

BENVENISTE, É. Problemas de Linguistica Geral I. São Paulo: Editora Nacional, Edusp, 1976.

BENVENISTE, É. Problemas de Linguística Geral II. São Paulo: Pontes Editores, 2006.

BORNETO, S. C'era una volta il metodo: tendenze attuali nella didatica delle lingue straniere. Roma: Carocci, 1998. 
BRASIL. Ministério da Educação. Parâmetros Curriculares Nacionais: língua estrangeira. Brasília: MEC, 1998.

BRASIL. Ministério da Educação. Base Nacional Comum Curricular. Brasília: MEC, 2007.

CAGNIN, A. L. Os quadrinhos. São Paulo: Ática, 1975.

DOLZ, J.; PASQUIER, A.; BRONCKART, J. P. L'acquisition des discours: Émergence d'une competence ou apprentissage de capacités langagière? Études de Linguistique Appliquée, v. 92, p. 23-37, 1993.

KERNERMAN, L. Password: English dictionary for speakers of Portuguese. São Paulo: Martins Fontes, 2005.

LEONTIEV, A. N. Le développement du psychisme. Paris: Edition Sociales, 1984. LERNER, D. Ler e escrever na escola: o real, o possivel e o necessário. Porto Alegre: Artmed, 2002.

MACHADO, R.; CAMPOS, T. R.; SAUNDERS, M. C. História do ensino de línguas no Brasil: avanços e retrocessos. 2007. Disponivel em: http:/ /www.helb.org.br/ index.php?option=com_content\&view $=$ article\&id=98: historia-do-ensino-de-linguas-no-brasil-avancos-e-retrocessos\&catid=1022:ano-1-no-01-12007\&Itemid =12. Acesso em: $1^{\circ}$ abr. 2019 .

MENDONÇA, M. R. S. Um gênero quadro a quadro: a história em quadrinhos. In: DIONISIO, A. P.; MACHADO, A. R.; BEZERRA, M. A. Gêneros textuais \& ensino. São Paulo: Parábola, 2010.

PICHIASSI, M. Fondamenti di glottodidattica: temi e problemi della didattica linguistica. Roma: Guerra Edizioni, 1999.

RAMOS, P. A leitura dos quadrinhos. São Paulo: Contexto, 2012.

SCHNEUWLY, B.; DOLZ, J. Gêneros orais e escritos na escola. Campinas: Mercado de Letras, 2004.

SILVA, T. T. Documentos de identidade: uma introdução às teorias do currículo. Belo Horizonte: Autêntica, 2013.

Recebido em 13 de novembro de 2018. Aprovado em 23 de março de 2019. 